regarding the making of curve sheets on blue-line cross-section paper with the necessary coördinates properly inked in. Drawings other than curves are usually sent in either as pencil sketches, or in blue-print form. In both of these cases the wax-cut process must be resorted to in order to reproduce the drawings. If, instead of pencil sketches or blue-prints, authors would send the original tracings, properly lettered to conform with Institute style and qualified to stand the necessary reducing, all these cuts could be made by the line-cut process at five cents per square inch, instead of by the wax-cut process at twenty cents per square inch.

\section{The Presentation or Papers Before the Institute}

For the benefit of those who desire to present papers before the Institute during the coming year and who may not be wholly familiar with the rules and customs of the Institute in such matters, the following explanation is given.

Although the advantage to the electrical profession of the stimulus, the educational influence and the development of esprit de corps, due to the influence of the Institute, is important and far reaching, yet the most serious direct effort of the Institute is the publication in its Proceedings and TransacTions of the fullest view of current electrical progress. Consequently, opportunity is gladly given for the presentation of all valuable matter of interest to the electrical profession when presented in the proper form.

According to the amended Constitution, the arranging of meetings, and the editing and approving of papers, lies with the Meetings and Papers Committee; all correspondence relating to papers should be there addressed.

Any person desiring to present a paper should so inform the committee as early as practicable, as the meetings are arranged some time in advance. It is the general plan of the committee not to assign dates for the reading of papers until the manuscript is received, so that papers may be published in full some time before the meeting to allow a careful preparation of discussion.

As the comments and criticisms on the papers, when well considered, generally add much to the value of the meetings, a few persons having especial authority or special knowledge are invited to start the discussion, which afterwards is thrown upon.

Written communication on any paper will be received within a reasonable time of the meeting, either before or after.

There are certain limitations as to what is gererally considered to constitute proper subject matter for presentation before the Institute.

(a) Only original papers will be received, i.e., papers previously published elsewhere cannot be presented before the Institute. Exception will be made in the case of the Institute Sections.

(b) Except in special cases, only matters of interest to a considerable portion of the Institute body can be presented at the regular monthly meetings. Other valuable matter will usually be reserved for the annual convention, or for special meetings.

(c) No matter intended merely to advertise any person or any particular make of apparatus is admissible.

(d) Space cannot usually be given to papers that are merely descriptive of apparatus or plants which do not involve new features. or important data not elsewhere available.

(e) Papers should as far as possible conform to the directions provided by the Meetings and Papers Committee as to typographical form, the use of abbreviations, character of cuts, etc. Copies of these directions can be obtained from the Committee, or from the Secretary of the Institute.

In all cases papers are subject to revision or rejection by the Meetings and Papers Committee.

It is earnestly requested, to permit of the most satisfactory arrangement of the program for the Institute meet- 
ings, and to lighten the work of the Committee, that all members contemplating the presentation of papers will give the earliest possible notice of their intention, and also complete the preparation of their manuscripts and send them to the committee promptly. It is probable that papers offered when the season is well advanced cannot be presented at any of the regular meetings during the present year.

Percy H. Thomas, Chairman Meetings \& Papers

Committee.

\section{Sections and University Branches}

Toledo Section

The regular monthly meeting of Toledo Section of the American Institute of Electrical Engineers was held Friday evering, September 6, 1907, at the Boody House. In the absence of Chairman Nagel, Secretary Geo. E. Kirk presided.

Mr. Geo. J. Miller gave a very interesting talk on the history of the electric storage-battery, explaining the basic features of chemically formed and pasted plates. The rough usage to which batteries are subjected, as in automobile work, was pointed out, and how plates are designed to give efficiency and durability even under such trying circumstances. Specimens of different plates were shown. There was a general discussion.

\section{By-laws of the Toledo Section}

I. NAME-Under the Constitution of the American Institute of Electrical Engineers, and pursuant to authorization of its board of Directors May 21, 1907, this Toledo Section of the American Institute of Electrical Engineers is organized.

II. Officers--The officers of this Section shall be a chairman, secretary, and three additional members constituting an executive committee of five.

1. Election of officers. The members of the Section shall vote by ballot for the five members of the executive committee.

2. Term of office. The executive committee shall be elected at the regular January meeting of each year for a term of one year.

3. Meetings of the executive committee. The executive committee shall meet wherever called by the chairman or a majority of its members.

4. Organization of executive committee. The chairman of the Section shall be chairman of the executive committee and the secretary of the Section shall be secretary of the executive committee.

III. Meetings. The Section shall hold a regular meeting at 8:00 p. $\mathrm{m}$. on the first Friday of each month at such place as the secretary may designate in the notice. Special meetings may be held upon call of the chairman or a majority of the executive committee, details as to time and place to be given in notice.

IV. Government. In deciding questions of government of Section and procedure therein, the Constitution of the Institute, the By-laws of the Institute, these By-laws of this section and Robert's Rules of Order, shall be followed in the order named.

V: Amendmen's. These By-laws may be amended by a majority of the members present at any regular meeting held after notice has been given that the amendment is to be considered.

VI. Adoption. These By-laws shall be in force when adopted by a majority of the members present at regular September 1907, meeting.

\section{Associates Elected}

At a regular meeting of the Board of Directors held in the Engineers' Building, 33 West Thirty-ninth street, New York, Friday, September 27, 1907, at 3:30 p.m., the following 60 Associates were elected:

Ashworth, Edward Montague, Engineer, Canadian General Electric Co.; res., 1584 Brunswick Ave., Toronto, Ont. 